\title{
STOCHASTIC LONG MEMORY IN TRADED GOODS PRICES
}

\author{
John T. Barkoulas \\ Department of Economics \\ Boston College \\ Chestnut Hill, MA 02167 USA \\ tel. $617-552-3682$ \\ fax 617-552-2308 \\ email: barkoula@bcaxp1.bc.edu
}

\section{Christopher F. Baum}

Department of Economics

Boston College

Chestnut Hill, MA 02167 USA

tel. 617-552-3673

fax 617-552-2308

email: baum@bc.edu

\section{Gurkan S. Oguz}

Department of Economics

Tufts University

Medford, MA 02155 USA

tel: 617-627-3560

\begin{abstract}
Using spectral regression and exact maximum likelihood methods, we test for long memory dynamics in the traded goods prices for the G7 countries, as measured in their import and export price indices. Significant and robust evidence of fractional dynamics with long memory features is found in both import and export price inflation rates.
\end{abstract}




\section{Introduction}

The presence of long memory in international inflation rates has been established in a number of studies. Baillie, Chung, and Tieslau (1996) found strong evidence of long memory in the inflation rates for the G7 countries (with the exception of Japan) and those of three high inflation countries: Argentina, Brazil, and Israel. Similar evidence of strong long term persistence in the inflation rates of the U.S., U.K., Germany, France, and Italy was also provided by Hassler and Wolters (1995). Baum and Barkoulas (1996) found evidence of long memory in both CPI- and WPI-based inflation rates for a large number of industrial and developing countries. International inflation rates are neither $I(0)$ nor $I(1)$ processes, but rather possess a fractional exponent between zero and one. The interpretation of this evidence suggests that inflation rates are mean reverting processes, so that an inflationary shock will persist, but will eventually dissipate.

This paper extends the literature by investigating the low frequency properties of the traded goods price component of the overall price index for the G7 countries. The unit values of imports and exports are of particular importance in international finance. A prime example is their usage in estimating "pass-through" equations which summarize the pricing behavior of firms trading in international markets (see, e.g., Helkie and Hooper (1987), Krugman and Baldwin (1987), and Warner and Kreinin (1983)). Conflicting evidence obtained from the application of standard unit root tests provides the motivation for testing for a fractional root. The fractional exponent in the differencing process of the import and export price indices is estimated using both spectral regression and exact maximum likelihood methods. 
The plan of the paper is as follows. Section 2 presents the estimation methods for the fractional differencing parameter. Data and empirical results are discussed in Section 3. We conclude in Section 4 with a summary of our results.

\section{Fractional Integration Tests}

The model of an autoregressive fractionally integrated moving average process of order $(p, d, q)$ with mean $\mu$, denoted by $\operatorname{ARFIMA}(p, d, q)$, may be written using operator notation as

$$
\Phi(L)(1-L)^{d}\left(y_{t}-\mu\right)=\Theta(L) u_{t}, \quad u_{t} \sim \text { i.i.d. }\left(0, \sigma_{u}^{2}\right)
$$

where $L$ is the backward-shift operator, $\Phi(L)=1-\phi_{1} L-\ldots-\phi_{p} L^{p}, \Theta(L)=1+$ $\vartheta_{1} L+\ldots+\vartheta_{q} L^{q}$, and $(1-L)^{d}$ is the fractional differencing operator defined by $(1-L)^{d}=\sum_{k=0}^{\infty} \frac{\Gamma(k-d) L^{k}}{\Gamma(-d) \Gamma(k+1)}$ with $\Gamma(\cdot)$ denoting the gamma (generalized factorial) function. The parameter $d$ is allowed to assume any real value. The arbitrary restriction of $d$ to integer values gives rise to the standard autoregressive integrated moving average (ARIMA) model. The stochastic process $y_{t}$ is both stationary and invertible if all roots of $\Phi(L)$ and $\Theta(L)$ lie outside the unit circle and $|d|<0.5$. The process is nonstationary for $d \geq 0.5$, as it possesses infinite variance (Granger and Joyeux (1980)). The correlation function of an ARFIMA process decays hyperbolically to zero contrary to the faster, geometric decay of a stationary ARMA process. For $d \in(0,0.5), \sum_{k=-n}^{n}|\rho(k)|$ diverges as $n \rightarrow \infty$, and the ARFIMA process is said to exhibit long memory. ${ }^{1}$ The process exhibits short memory for $d=0$, and intermediate memory or 
antipersistence for $d \in(-0.5,0)$. For $d \in[0.5,1)$ the process is mean reverting as there is no long run impact of an innovation to future values of the process.

One technique used to estimate the fractional differencing parameter $d$ is the spectral regression method of Geweke and Porter-Hudak (1983). They obtain an estimate of $d$ based on the slope of the spectral density function around the angular frequency $\omega=0$. The spectral regression is given by

$$
\ln \left\{I\left(\omega_{j}\right)\right\}=\ln f_{\varepsilon}(0)-d \ln \left\{4 \sin ^{2}\left(\omega_{j} / T\right)\right\}+\eta_{j}, \quad j=1,2, \ldots, v
$$

where $I\left(\omega_{j}\right)$ is the periodogram of $\mathbf{y}$ at the Fourier frequency $\omega_{j}=\frac{2 \pi j}{T}(j=0, \ldots, T-1), T$ is the number of observations, and $v=g(T) \ll T$ is the number of Fourier frequencies included in the spectral regression.

Sowell (1992a,b) developed a maximum likelihood (ML) estimation procedure for fractionally differenced models by deriving the unconditional exact ML function for a normally distributed stationary fractionally integrated time series. Let $Y_{T}=\left(y_{1}, y_{2}, \ldots, y_{T}\right)^{\prime}$ be the $T \times 1$ realization of a fractionally integrated time series $\left\{y_{t}\right\}$ generated by the process in (1) with normally distributed innovations. The log likelihood function for the sample of these $T$ observations is given by

$$
L\left(\gamma ; Y_{T}\right)=-\frac{T}{2} \log (2 \pi)-\frac{1}{2} \log \left|\sum_{T}\right|-\frac{1}{2}\left(Y^{\prime}{ }_{T} \sum_{T}^{-1} Y_{T}\right)
$$

The ML estimator, which is obtained by maximizing (3) with respect to the parameter vector $\gamma=(\Phi, \Theta, d)$, is consistent and asymptotically normal. The covariance function $\Sigma_{T}$ is a complicated function of the parameters of the model $\gamma$ and each evaluation of the likelihood function requires the inversion 
of the $(T \times T)$ matrix $\Sigma_{T}$, which is computationally costly. Sowell $(1992 \mathrm{a}, \mathrm{b})$ utilized the Toeplitz structure of $\Sigma_{T}$ to alleviate this burden. ${ }^{2}$

\section{Data and Empirical Estimates}

We perform the analysis on import and export price indices for the G7 countries. All data series are monthly observations covering the period 1957:1 to $1994: 12$ except for the import prices for the U.S. (1969:1 to 1994:12), export prices for the U.S. (1968:1 to 1994:12), and import and export prices for France (1962:1 to 1994:12). All data series were obtained from the IMF's International Financial Statistics database.

For each set of series, we initially investigate their low frequency properties by subjecting the series to the Phillips-Perron (PP: Phillips (1987), Phillips and Perron (1988)) and Kwiatkowski, Phillips, Schmidt, and Shin (KPSS, 1992) unit-root tests. Both tests check for integer orders of integration but they differ in terms of their null hypotheses. In the PP testing methodology, the unit-root null hypothesis is tested against the alternative of stationarity. In the KPSS test stationarity is the null hypothesis to be tested against the alternative of a unit root. The combined use of the PP and KPSS tests sheds more light on the integration order of the series. Tables 1 and 2 report the results obtained from applying the PP and KPSS tests to the growth rate (inflation rate) series. ${ }^{3}$ These tests provide conflicting evidence, as both the PP and KPSS tests reject their respective nulls for most of the series. Since neither an $I(1)$ nor an $I(0)$ process appears to adequately describe these series' low-frequency behavior, a fractionally differenced process may provide a more appropriate representation for these inflation rate series. 
Table 3 presents the spectral regression estimates of the fractional differencing parameter $d$ for the growth rates of the traded goods prices. We report fractional differencing estimates for $v=T^{0.50}, T^{0.55}$, and $T^{0.60}$ and impose the known theoretical variance of the regression error $\pi^{2} / 6$ in the construction of the $t$-statistic for $d$. The $d$ estimates for the import price inflation rates are significantly positive for all countries except France. Weaker evidence of long memory is obtained for exported price inflation rates, as the $d$ estimates are significantly positive for only the U.S., Canada, and Italy.

Table 4 presents the exact ML fractional differencing estimates for the inflation rates of traded goods prices. AR and MA polynomials up to order three are allowed for in the estimation process. The final ARFIMA model is selected on the basis of the Schwartz information criterion where we have ensured that stationarity and invertibility conditions are met. We have also checked for near-redundancies in the AR and MA polynomials. The MLE estimates are broadly consistent with the spectral regression estimates and more supportive of long memory. For import price inflation rates, there is strong evidence in favor of long memory for all countries except France, where only mild, yet statistically significant, evidence of long memory is found. Similar evidence in support of long memory is obtained for the export price inflation rates. Allowing for a fractional exponent in the differencing process of the inflation rates of traded goods prices reconciles the contradictory inference obtained from the PP and KPSS tests.

The implications of the long memory evidence in the inflation rates of import and export prices can be considered in both the time and frequency domains. In the time domain, long memory is indicated by the fact that the inflation rate series eventually exhibits positive dependence between distant observations. These series are not short memory processes, which would 
exhibit a rapid exponential decay in their impulse response weights. With the exception of the import price inflation series for the U.S. and Canada, we obtain stationary models $(d<0.5)$; these two series are nonstationary but mean reverting $(0.5<d<1)$. Such processes generate very slow, but eventual, decay in their impulse response weights. In the frequency domain, long memory is indicated by the fact that the spectral density becomes unbounded as the frequency approaches zero.

\section{Conclusions}

We tested for long memory in the unit values of imports and exports for the G7 countries using both the spectral regression method and Sowell's exact maximum likelihood method. We provided evidence of long term persistence in the inflation rates of import and export price indices. An ARFIMA model is established as an appropriate time series model for these series. These findings also have implications for the estimation of cointegrating relationships in systems of variables involving traded goods prices, such as the "pass-through" equations in international finance. 


\section{References}

Baillie, R. T., C.-F. Chung, and M. A. Tieslau (1996), Analysing inflation by the fractionally integrated ARFIMA-GARCH model, Journal of Applied Econometrics, 11, 23-40.

Baum, C. F. and J. T. Barkoulas (1996), Long term dependence in international inflation rates, Working Paper 333, Department of Economics, Boston College.

Fuller W. (1976), Introduction to Statistical Time Series, New York: John Wiley \& Sons.

Geweke J. and S. Porter-Hudak (1983), The estimation and application of long memory time series models, Journal of Time Series Analysis, 4, 221-238.

Granger, C. W. J. (1980), Long memory relationships and the aggregation of dynamic models, Journal of Econometrics, 25, 227-238.

Granger, C. W. J. and R. Joyeux (1980), An introduction to long-memory time series models and fractional differencing, Journal of Time Series Analysis, $1,15-39$.

Hassler, U. and J. Wolters (1995), Long memory in inflation rates: International evidence, Journal of Business and Economic Statistics, 13, 37-45.

Helkie, W. L. and P. Hooper (1987), The U.S. external deficit in the 1980s, International finance discussion paper no. 304, Board of Governors, Federal Reserve System, Washington, DC.

Hosking, J. R. M. (1981), Fractional Differencing, Biometrika, 68, 165-176.

Krugman, P. R. and R. E. Baldwin (1987), The persistence of the U.S. trade deficit, Brookings Papers on Economic Activity, 1, 1-43.

Kwiatkowski, D., P. C. B. Phillips, P. Schmidt, and Y. Shin (1992), Testing the null hypothesis of stationarity against the alternative of a unit root: 
How sure are we that economic time series have a unit root?, Journal of Econometrics, 54, 159-178.

Newey, W. and K. West (1987), A simple, positive semi-definite, heteroscedasticity and autocorrelation consistent covariance matrix, Econometrica, 55, 703-708.

Phillips, P. C. B. (1987), Time Series Regression with a Unit Root, Econometrica, $55,277-301$.

and P. Perron (1988), Testing for a Unit Root in Time Series Regression, Biometrika, 75, 335-346.

Sowell, F. (1992a), Maximum likelihood estimation of stationary univariate fractionally-integrated time-series models, Journal of Econometrics, 53, 165-188.

Sowell, F. (1992b), Modeling long-run behavior with the fractional ARIMA model, Journal of Monetary Economics, 29, 277-302.

Warner, D. and M. E. Kreinin (1983), Determinants of international trade flows, Review of Economics and Statistics, 65, 96-104. 


\section{Notes}

${ }^{1}$ Some authors refer to a process as a long memory process for all $d \neq 0$.

${ }^{2}$ We are grateful to Fallaw Sowell for providing computer programs to implement this methodology.

${ }^{3}$ Application of both tests to the log levels of the import and export price indices suggests the presence of a unit root as the PP tests fail to reject the unit root null while the KPSS test rejects its null of stationarity. These results are not presented here but are available on request. 
Table 1: Phillips-Perron (PP) Unit Root Test Results for the Inflation Rates of Traded Goods Prices

\begin{tabular}{lcccc}
\hline \hline & \multicolumn{2}{c}{$Z(\tilde{\alpha})$} & \multicolumn{2}{c}{$Z(t \tilde{\alpha})$} \\
\hline Series & $l=6$ & $l=12$ & $l=6$ & $l=12$ \\
\hline \hline Imports & & & & \\
U.S. & $-277.1^{* * *}$ & $-342.7^{* * *}$ & $-13.66^{* * *}$ & $-14.71^{* * * *}$ \\
Canada & $-526.3^{* * *}$ & $-628.7^{* * *}$ & $-23.00^{* * *}$ & $-23.29^{* * *}$ \\
Germany & $-448.3^{* * *}$ & $-493.3^{* * *}$ & $-19.63^{* * *}$ & $-19.95^{* * *}$ \\
U.K. & $-329.1^{* * *}$ & $-360.2^{* * *}$ & $-15.92^{* * *}$ & $-16.28^{* * *}$ \\
France & $-440.0^{* * *}$ & $-466.7^{* * *}$ & $-20.13^{* * *}$ & $-20.24^{* * *}$ \\
Italy & $-460.2^{* * *}$ & $-521.4^{* * *}$ & $-19.51^{* * *}$ & $-20.01^{* * *}$ \\
Japan & $-452.5^{* * *}$ & $-524.1^{* * *}$ & $-18.80^{* * *}$ & $-19.49^{* * * *}$ \\
& & & & \\
Exports & & & & \\
U.S. & $-491.3^{* * *}$ & $-610.6^{* * *}$ & $-20.29^{* * *}$ & $-21.25^{* * *}$ \\
Canada & $-484.0^{* * *}$ & $-602.1^{* * *}$ & $-20.05^{* * *}$ & $-21.03^{* * * *}$ \\
Germany & $-378.7^{* * *}$ & $-394.2^{* * *}$ & $-17.89^{* * *}$ & $-18.01^{* * * *}$ \\
U.K. & $-342.4^{* * *}$ & $-353.2^{* * *}$ & $-16.92^{* * *}$ & $-17.01^{* * * *}$ \\
France & $-432.0^{* * *}$ & $-447.8^{* * *}$ & $-20.31^{* * *}$ & $-20.36^{* * * *}$ \\
Italy & $-440.6^{* * *}$ & $-481.3^{* * *}$ & $-19.67^{* * *}$ & $-19.93^{* * *}$ \\
Japan & $-528.3^{* * *}$ & $-578.3^{* * *}$ & $-22.32^{* * *}$ & $-22.50^{* * *}$ \\
\hline \hline
\end{tabular}

Notes: The Phillips-Perron test statistics are $Z(\tilde{\alpha})$ and $Z(t \tilde{\alpha})$, which are obtained from regressing the time series on an intercept, time trend, and its lagged value. See Perron (1987) and Phillips and Perron (1988) for details on the tests. $l$ stands for the order of serial correlation allowed in constructing the test statistics. We used the lag window suggested by Newey and West (1987) to ensure positive semidefiniteness. The critical values for the $Z(\tilde{\alpha})(Z(t \tilde{\alpha}))$ test are $-29.5(-3.96),-21.8(-3.41)$, and -18.3 (3.12 ) at the $1 \%, 5 \%$, and $10 \%$ significance levels, respectively (Fuller (1976)). The superscript ${ }^{* * *}$ indicates statistical significance at the $1 \%$ significance level. 
Table 2: Kwiatkowski-Phillips-Schmidt-Shin (KPSS) Test Results for the Inflation Rates of Traded Goods Prices

\begin{tabular}{|c|c|c|}
\hline & \multicolumn{2}{|c|}{$\overline{(l)}$} \\
\hline Series & 6 & 12 \\
\hline \multicolumn{3}{|l|}{ Imports } \\
\hline U.S. & 0.096 & 0.070 \\
\hline Canada & $0.423^{* * *}$ & $0.307^{* * *}$ \\
\hline Germany & $0.248^{* * *}$ & $0.209^{* *}$ \\
\hline U.K. & $0.221^{* * *}$ & $0.184^{* *}$ \\
\hline France & $0.126^{*}$ & 0.113 \\
\hline Italy & $0.291^{* * *}$ & $0.235^{* * *}$ \\
\hline Japan & $0.290^{* * *}$ & $0.228^{* * *}$ \\
\hline \multicolumn{3}{|l|}{ Exports } \\
\hline U.S. & $0.142^{*}$ & 0.102 \\
\hline Canada & $0.331^{* * *}$ & $0.233^{* * *}$ \\
\hline Germany & 0.130 * & 0.118 \\
\hline U.K. & $0.159^{* *}$ & $0.146^{* *}$ \\
\hline France & 0.097 & 0.091 \\
\hline Italy & $0.220^{* * *}$ & $0.187^{* *}$ \\
\hline Japan & $0.131^{*}$ & 0.112 \\
\hline
\end{tabular}

Notes: $\eta_{\tau}=\frac{t=1}{s^{2}(l)}$ is the test statistic for the null hypothesis of trend stationarity, where $S_{t}=\sum_{i=1}^{t} e_{i}, t=1,2, \ldots, T$ (partial sum process of the residuals) with $\left\{e_{t}\right\}_{1}^{T}$ being the residuals from the regression of the series on an intercept and a linear time trend, and $s^{2}(l)$ is a consistent estimate of the "long-run variance". The estimator used here is of the form

$$
s^{2}(l)=T^{-1} \sum_{t=1}^{T} e_{t}^{2}+2 T^{-1} \sum_{s=1}^{l} w(s, l) \sum_{t=s+1}^{T} e_{t} e_{t-s}
$$

where $w(s, l)$ is an optimal lag window and $l$ is the order of serial correlation allowed. We used the lag window suggested by Newey and West (1987) to ensure positive semidefiniteness of $s^{2}(l)$. The test is an upper-tail test and the critical values are 0.216, 0.146, and 0.119 at the $1 \%, 5 \%$, and $10 \%$ significance levels, respectively (Kwiatkowski, Phillips, Schmidt, and Shin (1992)). The superscripts ${ }^{* * *},{ }^{* *},{ }^{*}$ indicate statistical significance at the $1 \%, 5 \%$, and $10 \%$ significance levels, respectively. 
Table 3: Spectral Regression Estimates of the Fractional-Differencing Parameter $d$ for the Inflation Rates of Traded Goods Prices

\begin{tabular}{|c|c|c|c|}
\hline Series & $d(0.50)$ & $d(0.55)$ & $d(0.60)$ \\
\hline \multicolumn{4}{|l|}{ Imports } \\
\hline U.S. & $\begin{array}{l}0.612 \\
(3.039)^{* * *}\end{array}$ & $\begin{array}{l}0.618 \\
(3.737)^{* * *}\end{array}$ & $\begin{array}{l}0.404 \\
(2.943)^{* * *}\end{array}$ \\
\hline Canada & $\begin{array}{l}0.500 \\
(2.853)^{* * *}\end{array}$ & $\begin{array}{l}0.412 \\
(2.820)^{* * *}\end{array}$ & $\begin{array}{l}0.422 \\
(3.533)^{* * * *}\end{array}$ \\
\hline Germany & $\begin{array}{c}0.328 \\
(1.873)^{*}\end{array}$ & $\begin{array}{l}0.398 \\
(2.723)^{* * *}\end{array}$ & $\begin{array}{l}0.285 \\
(2.386)^{* *}\end{array}$ \\
\hline U.K. & $\begin{array}{c}0.328 \\
(1.874)^{*}\end{array}$ & $\begin{array}{c}0.267 \\
(1.831)^{*}\end{array}$ & $\begin{array}{l}0.253 \\
(2.120)^{* *}\end{array}$ \\
\hline France & $\begin{array}{c}0.186 \\
(0.993)\end{array}$ & $\begin{array}{c}0.246 \\
(1.607)\end{array}$ & $\begin{array}{c}0.140 \\
(1.116)\end{array}$ \\
\hline Italy & $\begin{array}{l}0.341 \\
(1.947)^{*}\end{array}$ & $\begin{array}{l}0.524 \\
(3.586)^{* * *}\end{array}$ & $\begin{array}{c}0.399 \\
(3.339)^{* * *}\end{array}$ \\
\hline Japan & $\begin{array}{l}0.355 \\
(2.026)^{* *}\end{array}$ & $\begin{array}{l}0.318 \\
(2.180)^{* *}\end{array}$ & $\begin{array}{c}0.235 \\
(1.968)^{* *}\end{array}$ \\
\hline \multicolumn{4}{|l|}{ Exports } \\
\hline U.S. & $\begin{array}{l}0.712 \\
(3.535)^{* * *}\end{array}$ & $\begin{array}{l}0.596 \\
(3.600)^{* * *}\end{array}$ & $\begin{array}{l}0.437 \\
(3.246)^{* * *}\end{array}$ \\
\hline Canada & $\begin{array}{l}0.286 \\
(1.633)\end{array}$ & $\begin{array}{l}0.383 \\
(2.625)^{* * * *}\end{array}$ & $\begin{array}{c}0.483 \\
(4.051)^{* * * *}\end{array}$ \\
\hline Germany & $\begin{array}{c}0.207 \\
(1.182)\end{array}$ & $\begin{array}{c}0.182 \\
(1.247)\end{array}$ & $\begin{array}{c}0.115 \\
(0.968)\end{array}$ \\
\hline U.K. & $\begin{array}{c}0.337 \\
(1.924)^{*}\end{array}$ & $\begin{array}{c}0.212 \\
(1.452)\end{array}$ & $\begin{array}{c}0.280 \\
(2.345)^{*}\end{array}$ \\
\hline France & $\begin{array}{c}0.116 \\
(0.622)\end{array}$ & $\begin{array}{c}0.137 \\
(0.898)\end{array}$ & $\begin{array}{c}0.034 \\
(0.279)\end{array}$ \\
\hline Italy & $\begin{array}{c}0.318 \\
(1.813)^{*}\end{array}$ & $\begin{array}{l}0.384 \\
(2.631)^{* * *}\end{array}$ & $\begin{array}{l}0.243 \\
(2.035)^{* *}\end{array}$ \\
\hline Japan & $\begin{array}{c}0.002 \\
(0.016) \\
\end{array}$ & $\begin{array}{c}0.171 \\
(1.175) \\
\end{array}$ & $\begin{array}{c}0.095 \\
(0.798) \\
\end{array}$ \\
\hline
\end{tabular}

Notes: $d(0.50), d(0.55)$, and $d(0.60)$ give the $d$ estimates corresponding to the spectral regression of sample size $v=T^{0.50}, v=T^{0.55}$, and $v=T^{0.60}$, respectively. The known theoretical error variance of $\pi^{2} / 6$ is imposed in the construction of the $t$-statistic for the fractional differencing parameter $d$. 
Table 4: Maximum Likelihood Estimates of the Fractional-Differencing Parameter $d$ for the Inflation Rates of Traded Goods Prices

\begin{tabular}{|c|c|c|c|c|}
\hline \multirow[b]{2}{*}{ Price Series } & \multirow{2}{*}{$\begin{array}{c}\begin{array}{c}\text { Long } \\
\text { Memory } \\
\text { Parameter }\end{array} \\
d\end{array}$} & \multirow{2}{*}{$\begin{array}{c}\text { AR } \\
\text { Parameters } \\
\mathrm{AR}(1) \\
\end{array}$} & \multicolumn{2}{|c|}{ MA Parameters } \\
\hline & & & MA(1) & $\mathrm{MA}(2)$ \\
\hline \multicolumn{5}{|l|}{ Imports } \\
\hline U.S. & $\begin{array}{c}0.862 \\
(0.046)\end{array}$ & & $\begin{array}{l}-0.635 \\
(0.046)\end{array}$ & \\
\hline Canada & $\begin{array}{c}0.645 \\
(0.090)\end{array}$ & & $\begin{array}{l}-0.790 \\
(0.066)\end{array}$ & \\
\hline Germany & $\begin{array}{c}0.312 \\
(0.064)\end{array}$ & & $\begin{array}{l}-0.214 \\
(0.090)\end{array}$ & \\
\hline U.K. & $\begin{array}{c}0.231 \\
(0.040)\end{array}$ & & & \\
\hline France & $\begin{array}{c}0.046 \\
(0.029)\end{array}$ & & & \\
\hline Italy & $\begin{array}{c}0.175 \\
(0.031)\end{array}$ & & & \\
\hline Japan & $\begin{array}{c}0.152 \\
(0.035)\end{array}$ & & & \\
\hline \multicolumn{5}{|l|}{ Exports } \\
\hline U.S. & $\begin{array}{c}0.371 \\
(0.058)\end{array}$ & $\begin{array}{c}0.478 \\
(0.064)\end{array}$ & & \\
\hline Canada & $\begin{array}{c}0.463 \\
(0.120)\end{array}$ & $\begin{array}{c}0.615 \\
(0.078)\end{array}$ & $\begin{array}{c}0.237 \\
(0.115)\end{array}$ & $\begin{array}{l}-0.517 \\
(0.097)\end{array}$ \\
\hline Germany & $\begin{array}{c}0.130 \\
(0.037)\end{array}$ & & & \\
\hline U.K. & $\begin{array}{c}0.198 \\
(0.037)\end{array}$ & & & \\
\hline France & $\begin{array}{c}0.055 \\
(0.028)\end{array}$ & & & \\
\hline Italy & $\begin{array}{c}0.121 \\
(0.034)\end{array}$ & & & \\
\hline Japan & $\begin{array}{c}0.243 \\
(0.097)\end{array}$ & & $\begin{array}{l}-0.310 \\
(0.119)\end{array}$ & \\
\hline
\end{tabular}
\begin{tabular}{l}
\hline \hline Notes: The ML method is the exact ML method proposed by Sowell $(1992 a, b)$. Standard \\
errors appear in parentheses.
\end{tabular} 